\title{
Sequencing forgotten crops
}

GigaScience https://doi.org/10.1093/gigascience/giy152 (2018).

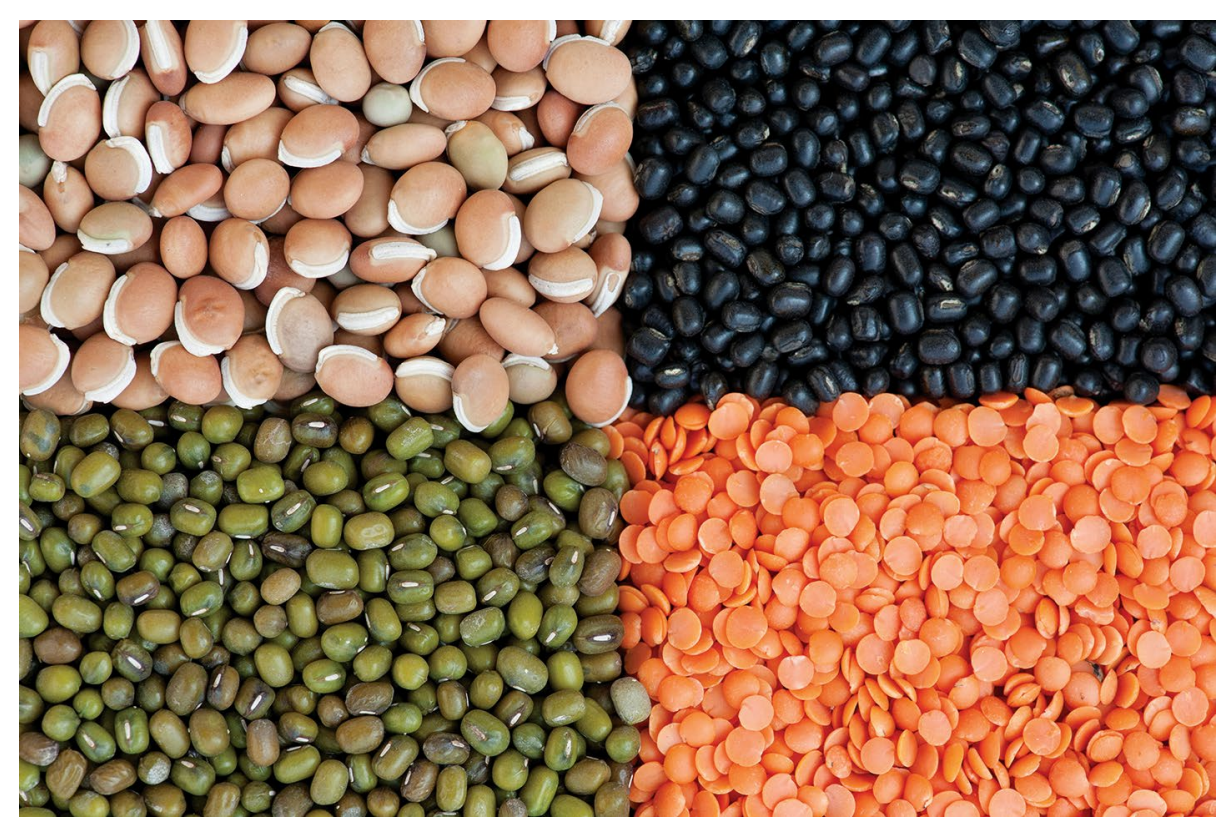

Credit: Tim Gainey / Alamy Stock Photo

We need more plants. Today, only a handful of global crops directly feed the better part of humanity. However, there are tens of thousands of edible plants on this planet. A significant portion of these are indigenous crops traditionally grown and used locally in rural societies by smallholder farmers. These plants, domesticated or not, are well adapted to their ecosystems, critical for local communities and mostly unknown to the outside world.

To boost interest and jump-start modern breeding research on these forgotten species, the African Orphan Crops Consortium aims to sequence and annotate a hundred promising African plants. Sequences from two legumes and three trees have just been released. These are multipurpose, drought-tolerant and highly nutritious plants, providing beans, nuts and fruits. The project includes local plants that are rich in vitamins, fibre, oil, micronutrients and proteins; can enrich the soil by hosting symbiotic microbes; and can also be used for medicinal use or animal feed.

Sequences are only an initial step. In the long term, research on neglected crops can lead to increases in yield, trade and growing range, as well as offering a more diverse diet and income supply to farmers' families. Higher diversity can make the agricultural production systems more sustainable and resilient to environmental changes such as climate or diseases, and boost food security. Let's not forget that rice, wheat, maize and potatoes were once locally adapted crops.

\section{Guillaume Tena}

Published online: 9 January 2019 https://doi.org/10.1038/s41477-018-0354-Z 